\title{
Fault Ride-Through Enhancement of PMSG Wind Turbines with DC Microgrids Using Resistive-Type SFCL
}

\author{
Doaa M. Yehia, Diaa-Eldin A. Mansour, Senior Member, IEEE, and Weijia Yuan
}

\begin{abstract}
Integrating permanent magnet synchronous generator (PMSG) wind turbines with DC microgrids have attracted a great attention due to the inherent merits of DC systems. However, under fault conditions, the excessive energy during fault will be reflected on PMSG rotating parts causing over-speed, mechanical stresses and fast aging. Also, large fault currents will force generator-side converter to disconnect making it not complied with grid codes. Accordingly, this paper aims to apply superconducting fault current limiter (SFCL) to enhance the performance of PMSG wind turbines with DC microgrids under fault conditions. PSCAD/EMTDC software is used to build the system under study that includes PMSG, controlled AC/DC converter, SFCL and DC bus. The behavior of SFCL in enhancing the DC output of the converter is first studied. Then, the impact of using SFCL on the speed, torque, and output current of PMSG is investigated and discussed. Finally, the suitable current limiting resistance is adopted considering DC output as well as PMSG speed.
\end{abstract}

Index Terms-PMSG wind turbines, DC microgrids, superconducting fault current limiter, current limiting resistance.

\section{INTRODUCTION}

I $\mathrm{N}$ recent years, wind energy has been expanded extensively worldwide and became one of the fastest growing energy sources due to its cleanness and sustainability. This accelerated the development and integration of wind turbine generators with the grid. Wind energy is the second contributor to the increment in renewable energy generation after hydro energy. By 2040, wind energy is projected to account for about $23 \%$ of total renewable energy generation all over the world [1]. Coupled with this, the concept of microgrid has been proposed to incorporate different renewable energy sources in a single framework capable of operation either in isolated mode or in grid connected mode [2]. In this regard, DC microgrids have attracted a great attention due to the DC nature of most renewable energy sources and energy storage devices [3-5]. Even with wind energy, connection to a DC microgrid will save one DC-AC conversion stage and will eliminate the requirements of frequency control and reactive power control.

This work was supported from the British Council through Newton Fund 216435894.

(Corresponding author: Doaa M. Yehia.)

Doaa M. Yehia and Diaa-Eldin A. Mansour are with the Department of Electrical Power and Machines Engineering, Faculty of Engineering, Tanta University, Tanta 31521, Egypt (e-mail: dmyehia@f-eng.tanta.edu.eg and mansour@f-eng.tanta.edu.eg).

Weijia Yuan is with the Department of Electronic and Electrical Engineering,University of Bath, Bath BA2 7AY, U.K. (e-mail: W.Yuan@bath.ac.uk).
There are different types of wind turbine generators. Among them, permanent magnet synchronous generator (PMSG) has gained popularity with large wind farms due to its brushless construction, high reliability, high efficiency, and so on [6]. With DC microgrids, the usage of PMSG becomes more feasible due to the saving of inverter stage as mentioned above. However, integration of PMSG with DC microgrids faces some technical problems under grid disturbances. The major problem of integrating PMSG with DC microgrids is fault response. In DC microgrids, DC faults cause a relatively large voltage drop with high levels of fault currents [7]. This results in a large contribution of fault current from PMSG with a negative impact on fault ride-through (FRT) capability and failure probability of power electronic switches.

Several studies have been carried out for performance assessment and FRT enhancement of PMSG under faults when interfaced with AC grids [8,9]. Most of these studies focus on dissipation of excessive energy in the DC-link. On the other hand, superconducting fault current limiter (SFCL) was used in [10] to improve FRT capability of PMSG connected to AC grids through minimizing the mismatch between generator power and grid-side power and subsequent decreasing the overvoltage on the DC-link capacitor. In [11], it was proposed to store the excessive energy in the rotating parts of the generator. But, this results in mechanical stresses and faster aging due to over-speeding of the generator. Also, at high wind speeds, the over-speed relay can be triggered due to violation of its allowed range. Unlike AC grids, fault behavior of PMSG interfaced with DC microgrids is different. In this case, the DC bus itself becomes faulty and the excessive energy will be reflected directly on the rotating parts of the generator. In addition, the large fault currents will force generator-side converter to disconnect.

This paper proposes the usage of resistive-type SFCL for FRT enhancement of PMSG wind turbines with DC microgrids. Resistive-type SFCL is considered because any inductance will affect the operation during normal conditions, and also, will have no beneficial impact during fault conditions, where inertia of PMSG and control of rectifier limits the high rising rate of current. This is different than that studied in [12] and [13]. Regarding FRT enhancement of wind turbine generators, SFCL has been used effectively for this purpose with AC grids $[14,15]$. Also, SFCL has been succeeded in reducing fault currents in DC systems [16]. In this study, PMSG and SFCL are built on PSCAD/EMTDC software, and then, 


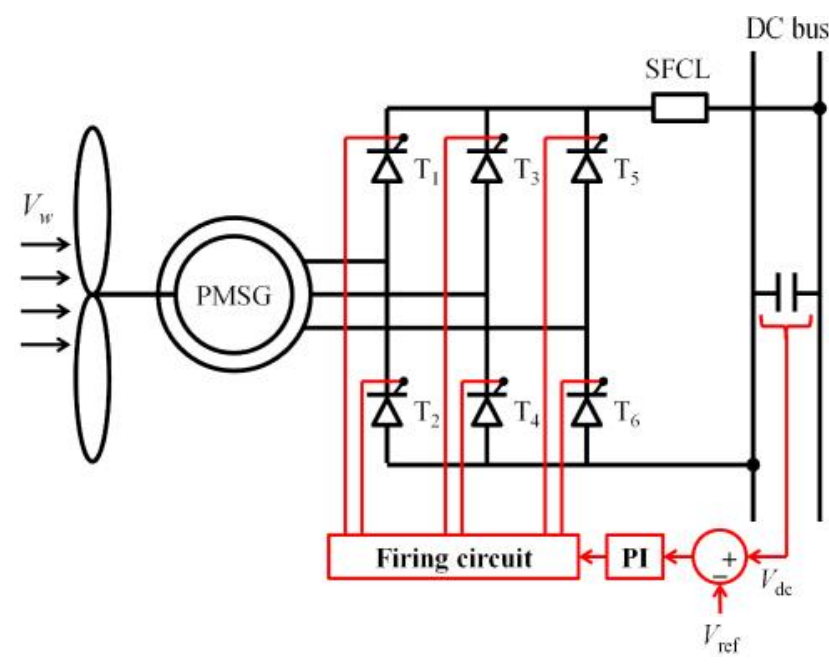

Fig. 1. Scheme of considered PMSG with a DC microgrid.

were interfaced with a DC bus through controlled AC-DC converter. First, the current limiting behavior of SFCL under DC fault is investigated. Then, the effect of using SFCL on PMSG performance is evaluated considering generator speed and torque as well as output 3-phase current. Finally, the performance is evaluated with different values of limiting resistances in order to adopt the suitable value.

\section{SYSTEM MODELING AND DESCRIPTION}

The wind energy system shown in Fig. 1 is composed of wind turbine, PMSG, and the rectifier stage that converts the variable frequency output of the generator to a controlled DC output at the desired value.

The extracted mechanical power from wind turbine can be described by the following equation:

$$
P_{w}=\frac{1}{2} \rho A C_{p}(\lambda, \beta) V_{w}^{3}
$$

where $\rho$ denotes to air density, $A$ denotes to swept area, $C_{\mathrm{p}}$ is the power coefficient for a certain tip speed ratio $\lambda$ and pitch angle $\beta$, and $V_{\mathrm{w}}$ is the wind speed. The developed torque is transferred to the rotor of the generator through the coupling shaft. The dynamic model of PMSG is described by the following equations in the $d q$ reference frame [17]:

$$
\begin{aligned}
& v_{d}=-i_{d} R_{s}-\omega \lambda_{q}-\frac{d \lambda_{d}}{d t} \\
& v_{q}=-i_{q} R_{s}+\omega \lambda_{d}-\frac{d \lambda_{q}}{d t} \\
& \lambda_{d}=L_{d} i_{d}+\lambda_{m} \\
& \lambda_{q}=L_{q} i_{q}
\end{aligned}
$$

where $v_{d}$ and $v_{q}$ are the $d q$ components of stator voltage, $R_{s}$ is stator winding resistance, $\omega$ is the rotational speed of PMSG, $\lambda_{d}$ and $\lambda_{q}$ are the $d q$ components of stator flux, $L_{d}$ and $L_{q}$ are the $d q$ components of stator winding inductance, and $\lambda_{m}$ is the permanent magnet flux linkage. The PMSG was rated at 50 $\mathrm{kVA}$ and $400 \mathrm{~V}$.

The rectifier is a 3-phase fully controlled Graetz bridge [18]. The output DC voltage is compared to the reference one, and then, the error is fed to PI controller and firing circuit as shown in Fig. 1. The gating signals for each switch are generated based on ramp comparison control. The firing angle $a$ is then used to control the output DC voltage $V_{\mathrm{dc}}$ as follows:

$$
V_{\mathrm{dc}}=1.35 V_{\mathrm{L}} \cos \alpha
$$

where $V_{\mathrm{L}}$ is the line input voltage.

The SFCL is represented by a current controlled switch paralleled with a nonlinear resistance [19]. The current controlled switch is normally closed to represent superconducting state. Once the current exceeds the critical value the switch changed to off state. The critical value was set at 150 A corresponding to $125 \%$ of DC rated current, whose value is $120 \mathrm{~A}$. The considered tape for developing SFCL is YBCO coated conductor [20]. The nonlinear resistance is operated into two modes; flux flow mode and resistive mode. The flux flow resistivity $\left(\rho_{f}\right)$ is expressed as follows:

$$
\rho_{f}=\frac{E_{c}}{J_{c}}{\frac{J}{J_{c}}}^{n}
$$

where $E_{c}$ is the critical electric field intensity and $n$ is a constant value. Usually $n$ is higher than 20 [20]; thus, the current limiting resistance after quenching will be governed mainly by the stabilizer resistance. The recovery time was neglected, since overcurrent ratio is small due to buffering action of the controlled rectifier.

Usually DC microgrids include other sources in addition to wind turbine generators, such as photovoltaic (PV) panels and battery energy storage systems (BESS). But, PV panels have a self-limited fault current. Moreover, BESS is a static source and come into operation directly after fault clearance. So, the focus in this study will be on FRT enhancement of PMSG connected to the DC microgrid with neglecting the contribution of other sources. Accordingly, the DC microgrid model is simplified as a DC bus incorporating a capacitor of $4700 \mu \mathrm{F}$. A resistive load of $45 \mathrm{~kW}$ was connected on the DC bus.

\section{RESUltS AND DISCUSSION}

\section{A. SFCL behavior}

To assess the performance of PMSG with DC microgrids when integrating SFCL, results were obtained considering SFCL resistance of 3 . This value lies within the common resistance range used for current limitation in DC systems [13]. Assuming that a solidly grounded DC fault occurs on the DC bus at $t=2 \mathrm{~s}$, the DC current and power at the converter terminals are depicted in Fig. 2.

When the fault occurred, the generator was loaded by about $46 \mathrm{~kW}$ corresponding to a DC current of about $115 \mathrm{~A}$. This loading condition is close to the full load of the generator that equals to $50 \mathrm{kVA}$. It is considered that protection devices isolate the fault after $0.1 \mathrm{~s}$. Upon the fault occurrence, the DC current increased instantaneously to $215 \mathrm{~A}$, and after about 13 $\mathrm{ms}$ it dropped gradually to zero. This is attributed to loosing controllability of the bridge rectifier after firing angles went to their limits. Also, the DC power dropped to zero during fault. On the other hand, the DC voltage depicted in Fig. 3 dropped to zero during fault and was kept at zero for about $0.4 \mathrm{~s}$ after 


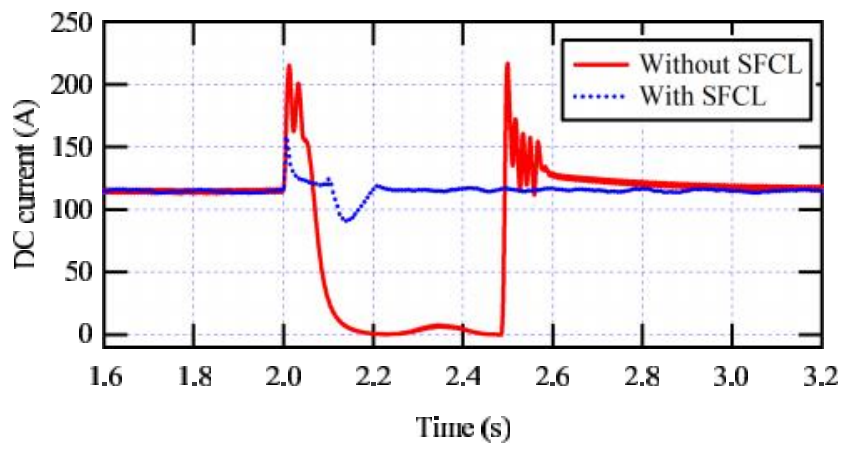

(a) Uutput DC current

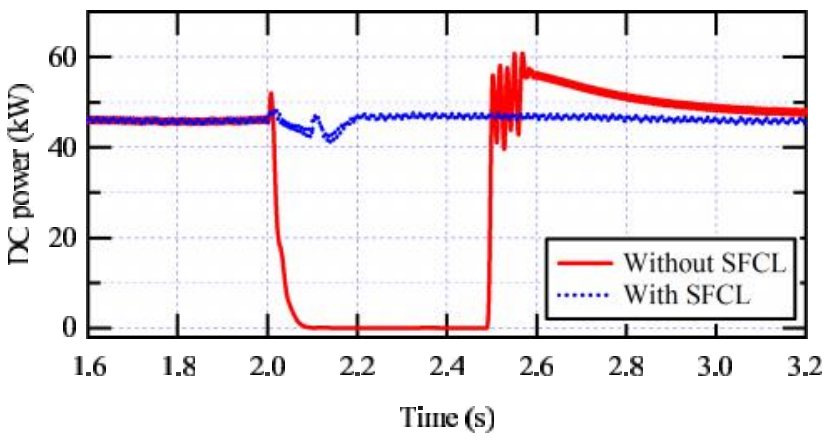

(b) Uutput DC power

Fig. 2. Behavior of SFCL in enhancing the DC output of PMSG converter.

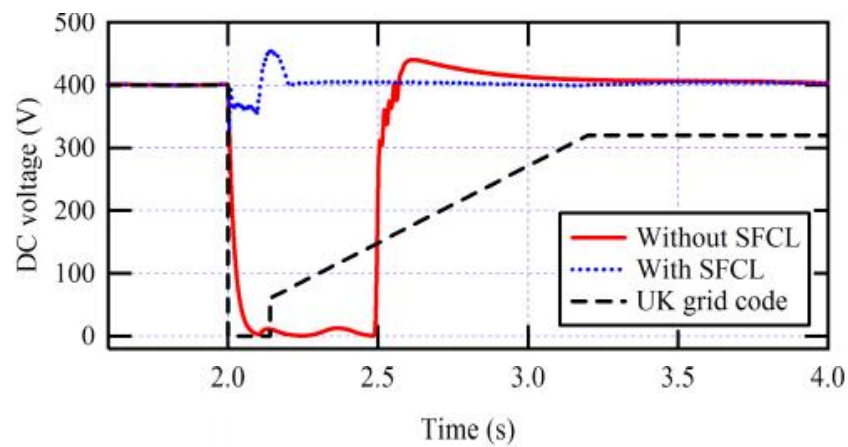

Fig. 3. Output voltage of PMSG converter in comparison of UK grid code.

the fault clearance at $2.1 \mathrm{~s}$, until PMSG could rebuild up the voltage. This makes the system not complied with various grid codes [21]. Fig. 3 compares the obtained voltage profiles with UK grid code as an example.

When SFCL was applied, the DC current was limited to 159 A with a significant reduction in the DC voltage drop that became only about $20 \%$. This action preserved the operation of PMSG in delivering power to the DC side as shown in Fig. 2(b), and made the system complied with the grid code. After fault clearance at $2.1 \mathrm{~s}$, the remaining charges on the DC-link capacitor cause a slight overvoltage on the DC bus.

\section{B. Impact of SFCL on PMSG performance}

The PMSG performance is evaluated by investigating both electrical and mechanical parameters. Electrical parameters include output 3-phase current and electrical torque, while mechanical parameters include mechanical torque and generator speed.

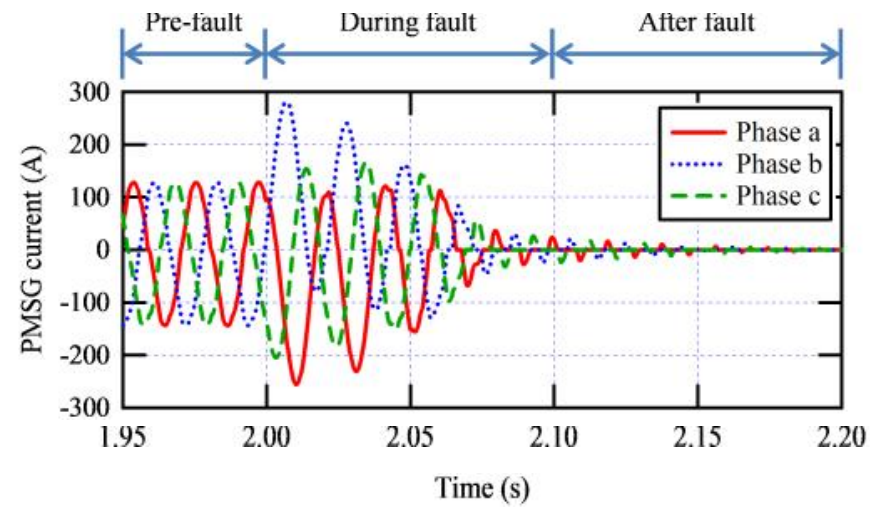

(a) Without SFCL

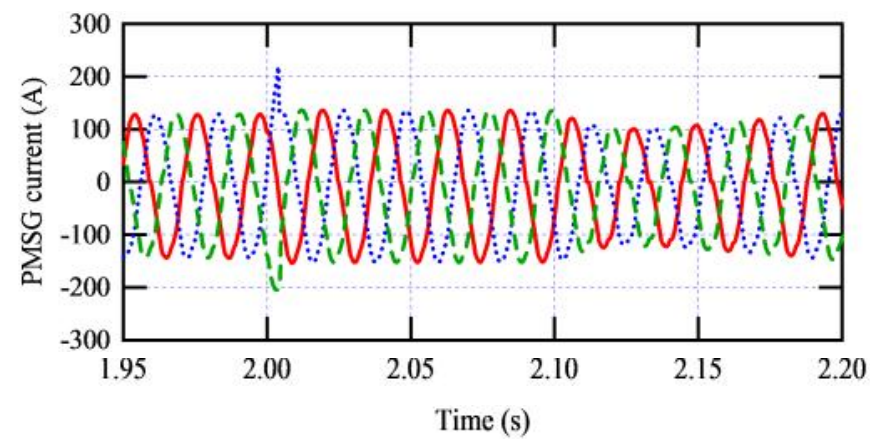

(b) With SFCL

Fig. 4. Impact of SFCL on the output 3-phase current of PMSG.

Fig. 4 illustrates the output 3-phase current of PMSG before and after applying SFCL. Before applying SFCL, the current increased instantaneously on all phases with different values depending on the instant of fault for each phase [22]. The maximum fault current occurred on phase $b$ with instantaneous value of $282 \mathrm{~A}$, which represents $220 \%$ of the nominal peak current. It is noteworthy that the nominal loading condition in this study is close to the full load of PMSG. If loading is lower than this value, the overcurrent percentage during fault will be higher. After applying SFCL, the 3-phase current increased slightly during fault. Another important point is that using SFCL enabled PMSG to continue delivering power to the DC side during the fault and fault clearance.

Regarding electrical and mechanical torques, they are presented in Fig. 5. Without SFCL, the electrical torque falls to zero during fault and continue at zero after fault clearance for about $0.4 \mathrm{~s}$. The mechanical torque falls smoothly due to the inertia of the generator. After $0.4 \mathrm{~s}$, the electrical torque is rebuilt and the mechanical torque follows it, but with longer time constant. With SFCL, both torques are kept around their pre-fault values. This is reflected positively on PMSG speed shown in Fig. 6. Before using SFCL, the generator exhibited over-speeding and reached above 1.2 p.u., while SFCL usage mitigated over-speeding effectively. These results can be explained as follows. When using SFCL, the drop in DC voltage becomes small. So, the 3-phase rectifier continues under control making a small drop in DC power. Consequently, the difference between input mechanical power from the turbine and output electrical power decreases and the excessive energy in 


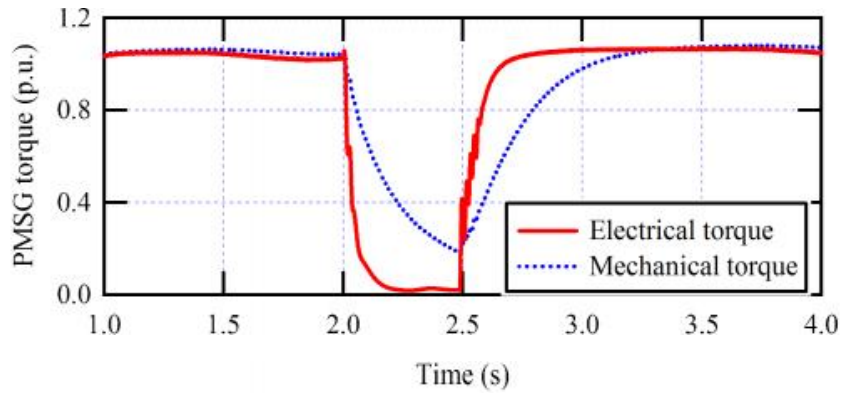

(a) Without SFCL

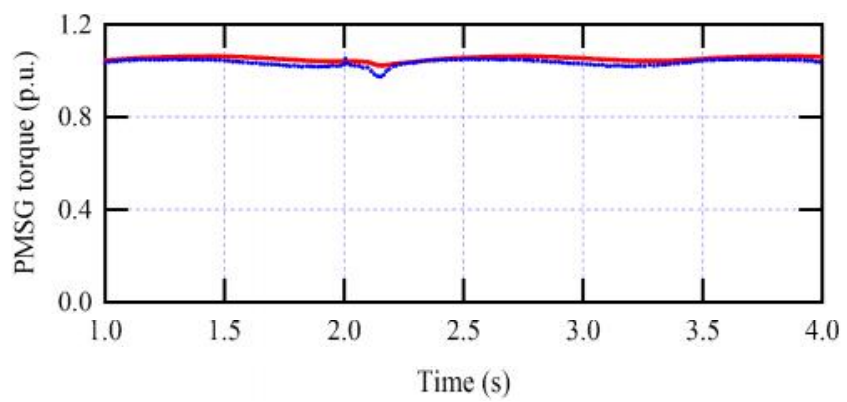

(b) With SFCL

Fig. 5. Impact of SFCL on the mechanical and electrical torque of PMSG.

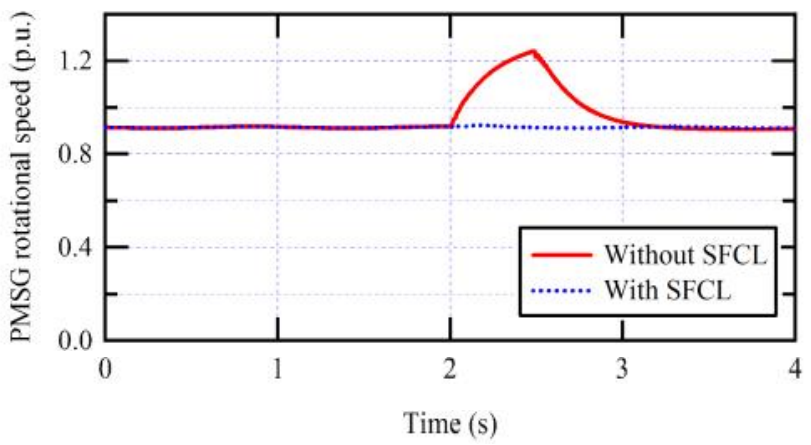

Fig. 6. Impact of SFCL on the PMSG rotational speed.

the rotating parts becomes limited. The power difference is a function of angular speed and inertia according to the following equation:

$$
P_{t}-P_{g}=J_{e} \omega_{m} \frac{d \omega_{m}}{d t}+P_{\mathrm{loss}}
$$

where $P_{t}$ and $P_{g}$ are the turbine power and generator power, respectively; $J_{e}$ is the inertia; $\omega_{m}$ is the rotational speed; and $P_{\text {loss }}$ is the generator power loss. It is clear that the decrease in power difference will be followed by a decrease in overspeeding.

\section{Effect of current limiting resistance}

As explained above, SFCL keep the electrical output power close to its nominal value. But, this condition will not be applicable for different SFCL resistances. So, it is expected that there a certain range of SFCL resistance that can be successful in performance enhancement of PMSG under DC faults. It is aimed in this section to examine the effect of current limiting resistance and recommend the suitable range for the considered PMSG in the current study.

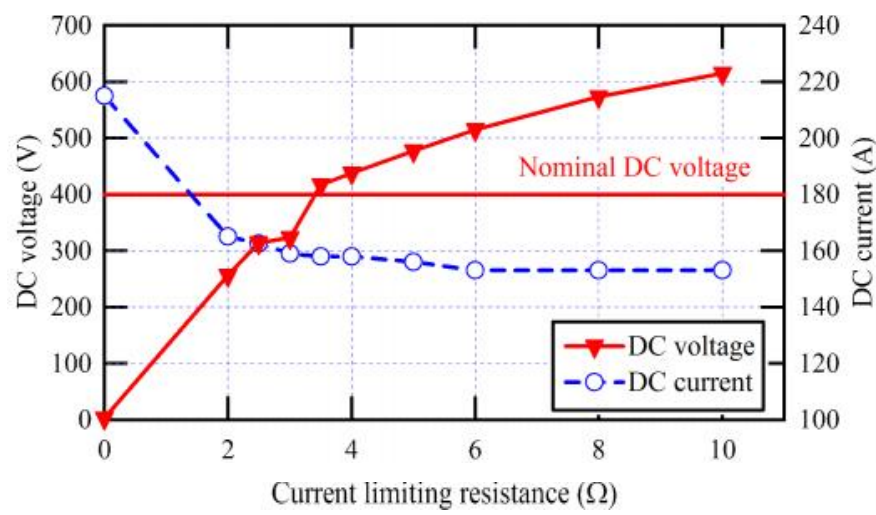

(a) Output DC voltage and current

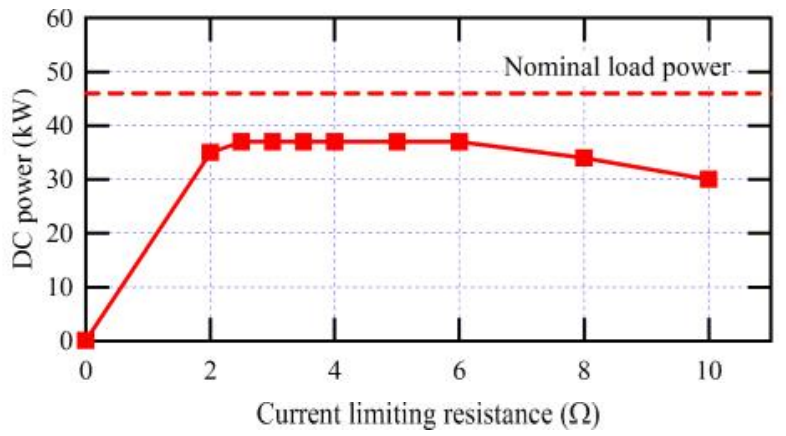

(b) Output DC power

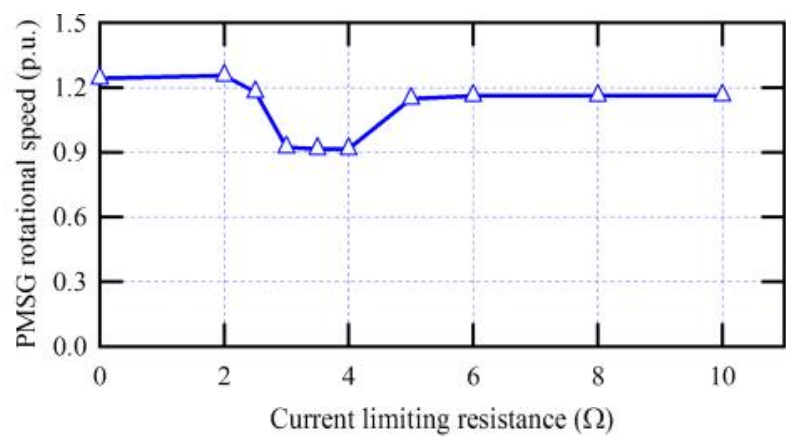

(c) PMSG rotational speed

Fig. 7. Effect of current limiting resistance on PMSG performance with DC microgrids.

Fig. 7 depicts the results of output DC parameters and PMSG speed with changing SFCL resistance. For DC voltage and current in Fig. 7(a), adding SFCL with 2 alleviated the voltage drop occurred without SFCL and increased the output DC voltage to $256 \mathrm{~V}$. Further increase of SFCL resistance increased the output voltage until reached around its nominal value $400 \mathrm{~V}$ at SFCL resistance of 3.5 . Additional increase of SFCL resistance above 3.5 caused an overvoltage. This overvoltage continued until reached about $615 \mathrm{~V}$ at 10 resistance. Regarding DC current, it was limited from 215 A without SFCL to $165 \mathrm{~A}$ at SFCL resistance of 2 . The limitation in current continued, and at about 3.5 limiting resistance, the current attained approximately constant value slightly above the critical current of SFCL.

This will be reflected on DC power and PMSG speed as shown in Fig. 7(b) and Fig. 7(c). The drop in DC power decreased with the increase in SFCL resistance, and above 6 it increased again but with slower rate. Correspondingly, PMSG 
speed decreased with increasing SFCL resistance and reached around 0.9 p.u. at 3 . Then it was kept around this value until limiting resistance of 4 . After that, PMSG was accelerated again and its speed reached about 1.16 p.u. for the remaining values of SFCL resistances. Based on these results, it can be claimed that the suitable range of SFCL resistance is 3 4.

\section{CONCLUSION}

In this study, SFCL was used for performance enhancement of PMSG wind turbines integrated with DC microgrids. The models of PMSG, SFCL, power converter and DC bus were built on PSCAD/EMTDC computer package. Then, detailed analysis was carried out to characterize SFCL behavior and its impact on PMSG performance. SFCL of limiting resistance 3 succeeded in limiting the DC current and decreasing the DC voltage drop making the system complied with various grid codes. This limiting action preserved the output DC power with a positive impact on PMSG developed torque and acceleration. With increasing SFCL resistance above 3.5 , adverse impact was observed on DC voltage and PMSG performance. The suitable SFCL resistance ranged between 3 and 4 .

\section{REFERENCES}

[1] U.S. Energy Information Administration, International Energy Outlook 2016, Chapter 5, pp. 84, 2016.

[2] A. Mehrizi-Sani and R. Iravani, "Potential-function based control of a microgrid in islanded and grid-connected modes," IEEE Trans. Power Syst., vol. 25, no. 4, pp. 1883-1891, Nov. 2010.

[3] D. M. Yehia, Y. Yokomizu, D. Iioka, R. Watanabe, and T. Matsumura, "A Novel approach to deliverable power in low-voltage DC distribution system on the basis of voltage stability," IEEJ Trans. Electr. Electronic Engineering, vol. 6, pp. 395-402, 2011.

[4] A. M. Dizqah, A. Maheri, K. Busawon, and A. Kamjoo, "A multivariable optimal energy management strategy for standalone dc microgrids," IEEE Trans. Power Syst., vol. 30, no. 5, pp. 2278-2287, Sept. 2015

[5] D. Kumar, F. Zare, and A. Ghosh, "DC microgrid technology: System architectures, AC grid interfaces, grounding schemes, power quality, communication networks, applications, and standardizations aspects," IEEE Access, vol. 5, pp. 12230-12256, 2017.

[6] H. Li and Z. Chen, "Overview of different wind generator systems and their comparisons," IET Renewable Power Generation, vol. 2, no. 2, pp. 123-138, June 2008.

[7] J. D. Park and J. Candelaria, "Fault detection and isolation in lowvoltage DC-bus microgrid system," IEEE Trans. Power Delivery, vol. 28, no. 2, pp. 779-787, Apr. 2013.
[8] J. F. Conroy and R. Watson, "Low-voltage ride-through of a full converter wind turbine with permanent magnet generator," IET Renewable Power Generation, vol. 1, no. 3, pp. 182-189, Sept. 2007.

[9] M. Nasiri and R. Mohammadi, "Peak current limitation for grid side inverter by limited active power in PMSG-based wind turbines during different grid faults," IEEE Trans. Sustain. Energy, vol. 8, no. 1, pp. 3-12, Jan. 2017.

[10] L. Chen, H. He, H. Chen, L. Wang, L. Zhu, Z. Shu, F. Tang, and J. Yang, "Study of a modified flux-coupling-type SFCL for efficient fault ride-through in a PMSG wind turbine under different types of faults," Canadian J. of Electrical and Computer Engineering, vol. 40, no. 3, pp. 189-200, 2017.

[11] M. F. M. Arani and Y. A. R. I. Mohamed, "Assessment and enhancement of a full-scale PMSG-based wind power generator performance under faults," IEEE Trans. Energy Convers., vol. 31, no. 2, pp. 728-739, June 2016.

[12] A. Morandi et al., "Design of a DC resistive SFCL for application to the $20 \mathrm{kV}$ distribution system," IEEE Trans. Appl. Supercond., vol. 20, no. 3, pp. 1122-1126, June 2010

[13] L. Chen, H. Chen, Z. Shu, G. Zhang, T. Xia and L. Ren, "Comparison of inductive and resistive SFCL to robustness improvement of a VSCHVDC system with wind plants against DC fault," IEEE Trans. Appl. Supercond., vol. 26, no. 7, Art. No. 5603508, Oct. 2016.

[14] M. E. Elshiekh, D. A. Mansour, and A. M. Azmy, "Improving fault ridethrough capability of DFIG-based wind turbine using superconducting fault current limiter," IEEE Trans. Appl. Supercond., vol. 23, no. 3, Art. No. 5601204, June 2013

[15] Z. C. Zou, X. Y. Chen, C. S. Li, X. Y. Xiao and Y. Zhang, "Conceptual design and evaluation of a resistive-type SFCL for efficient fault ride through in a DFIG," IEEE Trans. Appl. Supercond., vol. 26, no. 1, Art. No. 5600209, Jan. 2016.

[16] Q. Yang, S. L. Blond, F. Liang, W. Yuan, M. Zhang and J. Li, "Design and application of superconducting fault current limiter in a multiterminal HVDC system," IEEE Trans. Appl. Supercond., vol. 27, no. 4, Art. No. 3800805, June 2017.

[17] S. Li, T. A. Haskew, R. P. Swatloski, and W. Gathings, "Optimal and direct-current vector control of direct-driven PMSG wind turbines," IEEE Trans. Power Electron., vol. 27, no. 5, pp. 2325-2337, May 2012.

[18] K. R. Padiyar, HVDC power transmission systems, Second Revised Edition, New Age International Publishers, 2012.

[19] D. A. Mansour and D. M. Yehia, "Analysis of 3-phase superconducting fault current limiters in power systems with inhomogeneous quenching," IEEE Trans. Appl. Supercond., vol. 23, no. 3, Art. No. 5602605, June 2013.

[20] K. Nam, C. Lee, D. K. Park, T. K. Ko, and B. Y. Seok, "Thermal and electrical analysis of coated conductor under AC over-current," IEEE Trans. Appl. Supercond., vol. 17, no. 2, pp. 1923-1926, Jun. 2007.

[21] M. Tsili and S. Papathanassiou, "A review of grid code technical requirements for wind farms," IET Renew. Power Gener., vol. 3, no. 3, pp. 308-332, Sep. 2009.

[22] D. A. Mansour, "Effect of fault resistance on the behavior of superconducting fault current limiter in power systems", IEEE Int'l. Conf. Power and Energy (PECON), Malaysia, pp. 212-216, 2014. 